\title{
The Effect of Synthetic Cannabinoids on P-Wave Dispersion: An Observational Study
}

\author{
Esra Aydin Sunbul ${ }^{a}$ Murat Sunbul $^{b} \quad$ Ayse Terzi $^{a}$ Sumeyye Callia ${ }^{a}$ Esra Koca ${ }^{a}$ \\ Rabia Bilici $^{a}$ Serhat Citak ${ }^{a}$ \\ a Department of Psychiatry, Erenkoy Training and Research Hospital for Psychiatric and Neurological Disorders, and \\ ${ }^{b}$ Department of Cardiology, Faculty of Medicine, Marmara University, Istanbul, Turkey
}

\section{Key Words}

Cardiovascular risk · P-wave dispersion · Synthetic

cannabinoids

\begin{abstract}
Objective: The aim of this study was to investigate the effect of synthetic cannabinoids (SC) on P-wave dispersion (PD) in patients who consume SC. Materials and Methods: The study population included 72 patients who consumed SC and 36 age- and sex-matched healthy controls. The severity of addiction was detected using the addiction profile index (BAPI). The PD was measured by 12-lead ECG obtained upon admission to hospital. Statistical analyses were performed using the SPSS v20.0 statistical software package. Results: The mean age of the patients and controls was $26.9 \pm 7.0$ and $26.3 \pm 6.5$ years, respectively. Mean duration of SC consumption was $1.7 \pm 0.7$ years. Mean BAPI score of patients who consumed SC was $12.8 \pm 3.4$. Patients who consumed $\mathrm{SC}$ had a significantly higher PD value than controls ( $37.7 \pm$ 11.5 vs. $30.6 \pm 6.4 \mathrm{~ms}, \mathrm{p}<0.001)$. The BAPI score was significantly correlated with PD value $(r=0.675, p<0.001)$. In the linear regression model that included PD value, age and heart rate, PD value was significantly and independently cor-
\end{abstract}

\begin{tabular}{ll}
\hline KARGER & $\begin{array}{l}\text { ( } 2016 \text { S. Karger AG, Basel } \\
1011-7571 / 16 / 0255-0483 \$ 39.50 / 0\end{array}$ \\
$\begin{array}{l}\text { E-Mail karger@karger.com } \\
\text { www.karger.com/mpp }\end{array}$ & $\begin{array}{l}\text { This is an Open Access article licensed under the terms of the } \\
\text { Creative Commons Attribution-NonCommercial 3.0 Un- } \\
\text { ported license (CC BY-NC) (www.karger.com/OA-license), } \\
\text { applicable to the online version of the article only. Distribu- } \\
\text { tion permitted for non-commercial purposes only. }\end{array}$
\end{tabular}

related with BAPI score $\left(r^{2}\right.$ of the model $\left.=0.339 ; p<0.001\right)$. Conclusions: In this study, patients who consumed SC had significantly higher PD values than controls, and the BAPI score correlated with the PD value. Hence SC consumption could lead to an increased risk of cardiovascular disease through prolonged PD. We recommend the use of the simple and inexpensive ECG to assess cardiovascular risk in patients who consume SC.

๑) 2016 S. Karger AG, Basel

\section{Introduction}

Synthetic cannabinoids (SC) are manufactured in clandestine laboratories and sprayed on dried plant materials [1]. They were first marketed as a legal cannabis alternative in Europe in the early 2000s. SC consist of various chemical groups and subgroups. Due to structural diversity and similarity, laboratories have problems identifying the different compounds of the synthesized cannabinoid. Therefore, evaluation of the clinical effects of SC is difficult because of the unidentified substances contained in the SC. SC interact with the 2 subtypes of cannabinoid receptors, $\mathrm{CB} 1$ and $\mathrm{CB} 2$. The $\mathrm{CB} 1$ recep- 
tors are mainly expressed in the central and peripheral nervous systems, bone, heart, liver, lung, vascular tree and urogenital system, while CB2 receptors are mainly expressed in the immune system and central nervous system [1]. Due to a varying degree of affinity to these receptors, clinical effects are changeable. Although a few SC are structurally related to $\Delta 9$-tetrahydrocannabinol, the primary psychoactive component of cannabis, other SC belong to different chemical subgroups [1]. SC are cheaper and more easily available than other cannabinoids, and their popularity has increased due to their intense psychoactive effects and the lack of detectability in routine urine drug tests [1]. Hence SC consumption has become widespread, despite increased law enforcement and regulatory control measures [1]. Epidemiological data suggest that the majority of SC users are young adults who perceive $\mathrm{SC}$ as safer than noncannabinoid drugs [2].

The consumption of products containing SC may lead to serious adverse effects [3]. Previous studies show that psychiatric disorders may also lead to an increased risk of cardiovascular disease (CVD) [4-6]. There is a bidirectional relationship between CVD and depressive disorders [7]. Dysregulation of the autonomic nervous system is an important mechanism for this relationship $[8,9]$. Decreased heart rate variability and nondipper hypertension may lead to deterioration in the autonomic nervous system that includes increased sympathetic effect and abnormal parasympathetic activity, which may be the cause of increased risk of CVD $[8,9]$.

$\mathrm{P}$-wave dispersion (PD), defined as the time difference between the maximum and minimum of the $\mathrm{P}$ wave on 12-lead electrocardiography (ECG), is a noninvasive method of disorganized atrial repolarization. It was proposed to be used as a predictor of the increased risk of CVD [10, 11]. Previous studies show that PD is associated with psychiatric disorders including hypochondriasis, depression and panic disorder [12-14]. In a meta-analysis of PD values in healthy individuals, it was demonstrated that the mean $\mathrm{PD}$ value is $33.46 \pm 9.65 \mathrm{~ms}$ [15]. A previous study demonstrated that PD values of $>40 \mathrm{~ms}$ were found to be correlated with atrial fibrillation, with a sensitivity of $74-83 \%$ and specificity of $81-$ $85 \%$ [16]. Previous studies have shown SC may lead to increased risk of rhythm abnormalities $[17,18]$. Therefore, we hypothesized that SC could affect the ECG indices and PD might be one of the causes of rhythm abnormalities in these patients. Hence, the aim of this study was to investigate the effect of SC on PD in patients who consume SC.

\section{Materials and Methods}

\section{Study Population}

Eighty patients were initially enrolled in this study. The personally reported use of SC and/or in whom SC was detected in urine screening tests at the Erenkoy Mental and Neurological Diseases Training and Research Hospital. Sociodemographic data were collected using a questionnaire.

Exclusion criteria were: underlying cardiac conditions, abnormal ECG findings and consumption of psychotropic drugs or other medications that may interfere with an ECG test. Five patients were excluded because they took psychotropic drugs, and 3 had abnormal ECG findings. The remaining 72 patients were included in the study; 55 were single, 17 were married and 70 had graduated from primary school. The control group included 36 healthy age- and sex-matched volunteers. The investigation complied with the principles outlined in the Declaration of Helsinki. The study was approved by the Institutional Ethics Committee and written informed consent was obtained from all the participants. Physical examination findings, medical history data and resting 12-lead ECGs were obtained from all members of the study population. Laboratory findings in the medical records of the patients including glucose, creatinine, total cholesterol, low-density lipoprotein and thyroidstimulating hormone levels in the last 2 weeks before enrolment were also used. PD was measured by 12-lead ECG obtained upon hospital admission. A single experienced cardiologist (M.S.) who was unaware of the particular group evaluated the ECG records.

\section{Addiction Profile Index}

The severity of addiction was detected using the addiction profile index (BAPI) score. BAPI was validated by Ögel et al. [19] in 2012. The BAPI has 37 items and 5 subscales including the characteristics substance use, diagnosis, effect on daily life, craving severity and motivation. Total BAPI score was calculated as described previously [19]. The cut-off point of the BAPI score is 10.7. A score $<12$ shows a low level of addiction, 12-14 shows a moderate level of addiction and $>14$ shows a high level of addiction.

\section{ECG Measurements}

Following a resting period of $20 \mathrm{~min}, 12$-lead ECG was recorded in supine position at a paper speed of $50 \mathrm{~mm} / \mathrm{s}$ and an amplitude of $20 \mathrm{~mm} / \mathrm{mV}$ using a Nikon Kohden ECG device (Japan). The onset of $\mathrm{P}$-wave was defined as the point of first downward departure from the top of the baseline for negative waves. The return to the baseline of the bottom of the trace was considered to be the end of the P-wave. The difference between the maximum and minimum $\mathrm{P}$-wave duration calculated from any derivation of the 12-lead ECG was defined as the PD (PD = Pmaximum - Pminimum) [20].

\section{Statistical Analysis}

Statistical analyses were performed using the SPSS v20.0 statistical software package. Continuous data are expressed as mean \pm standard deviation while categorical data are presented as number and percentage of patients. The $\chi^{2}$ test and the Fisher exact test were used for the comparison of categorical variables while the Student $t$ test or the Mann-Whitney U test were used to compare parametric and nonparametric continuous variables, respectively. Correlation analysis was performed using the Spearman correlation test. Linear regression analyses were performed to determine the predictors of BAPI score. A value of $\mathrm{p}<0.05$ was considered statistically significant. 
Table 1. Sociodemographic data and clinical parameters of patients and controls

\begin{tabular}{lccc}
\hline & $\begin{array}{c}\text { Patients } \\
(\mathrm{n}=72)\end{array}$ & $\begin{array}{l}\text { Controls } \\
(\mathrm{n}=36)\end{array}$ & $\begin{array}{l}\text { Normal } \\
\text { range }\end{array}$ \\
\hline Age, years & $26.9 \pm 7.0$ & $26.3 \pm 6.5$ & - \\
Gender, male & 72 & 36 & - \\
Married & 17 & 8 & - \\
Not married & 55 & 28 & - \\
Working status & 45 & 26 & - \\
Completed primary school & 70 & 36 & - \\
Duration of SC use, years & $1.7 \pm 0.7$ & - & - \\
BAPI score & $12.8 \pm 3.4$ & - & - \\
Glucose, mg/dl & $91.9 \pm 13.6$ & $94.5 \pm 17.3$ & $65-110$ \\
Creatinine, mg/dl & $0.82 \pm 0.10$ & $0.81 \pm 0.11$ & $0-1.2$ \\
Total cholesterol, mg/dl & $170.0 \pm 30.7$ & $174.2 \pm 36.1$ & $80-200$ \\
LDL, mg/dl & $104.6 \pm 28.2$ & $103.9 \pm 35.5$ & $0-140$ \\
TSH, mIU/ml & $1.24 \pm 0.83$ & $1.63 \pm 0.67$ & $0.34-5.60$ \\
\hline
\end{tabular}

Values are expressed as $\mathrm{n}$ or means $\pm \mathrm{SD}$. LDL = Low-density lipoprotein; TSH = thyroid-stimulating hormone.

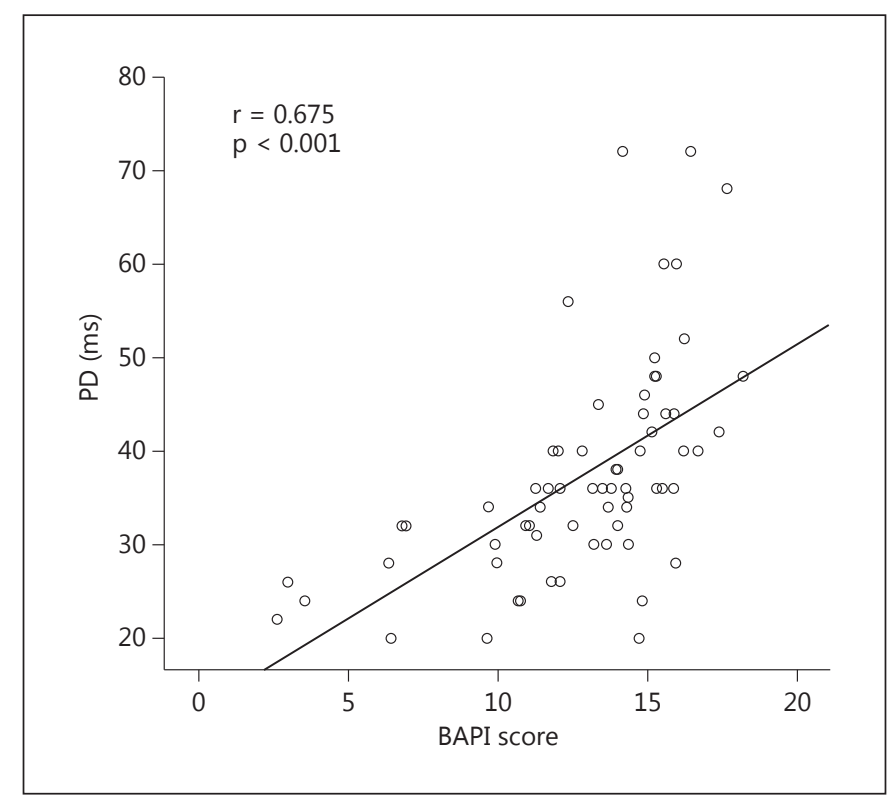

Fig. 1. PD significantly correlated with BAPI in patients who consumed SC.

\section{Results}

The mean age of the patients and the controls was 26.9 \pm 7.0 and $26.3 \pm 6.5$ years, respectively. Sociodemographic data and clinical parameters of patients who consumed SC and controls are shown in table 1. These data were similar in the 2 groups. Mean duration of use of SC was
Table 2. ECG parameters of the study population

\begin{tabular}{llll}
\hline & $\begin{array}{l}\text { Patients } \\
(\mathrm{n}=72)\end{array}$ & $\begin{array}{l}\text { Controls } \\
(\mathrm{n}=36)\end{array}$ & p value \\
\hline Heart rate, beats/min & $71.3 \pm 12.7$ & $71.8 \pm 8.3$ & 0.325 \\
P maximum, ms & $91.3 \pm 12.4$ & $90.7 \pm 9.4$ & 0.729 \\
P minimum, ms & $53.5 \pm 12.4$ & $60.1 \pm 11.4$ & 0.009 \\
PD, ms & $37.7 \pm 11.5$ & $30.6 \pm 6.4$ & 0.001 \\
\hline
\end{tabular}

Table 3. Linear regression analysis to determine the independent predictors of BAPI score

\begin{tabular}{lrrr}
\hline & \multicolumn{1}{c}{$\mathrm{t}$} & $\mathrm{p}$ value \\
\hline PD, ms & 0.581 & 5.650 & $<0.001$ \\
Age, years & -0.055 & -0.506 & 0.615 \\
Heart rate, beats/min & 0.092 & 0.842 & 0.403 \\
\hline
\end{tabular}

$1.7 \pm 0.7$ years. The mean BAPI score of the study population was $12.8 \pm 3.4$. The laboratory measurements are shown in table 1 . All laboratory measurements were within the normal range.

The ECG findings of the study population are given in table 2. Heart rate was similar in the 2 groups. Patients who consume SC have a significantly higher PD value than controls $(37.7 \pm 11.5$ vs. $30.6 \pm 6.4 \mathrm{~ms}, \mathrm{p}<0.001)$. Correlation analysis revealed that BAPI score was significantly correlated with $\mathrm{PD}$ value $(\mathrm{r}=0.675, \mathrm{p}<0.001$; fig. 1). Linear regression analysis was performed to determine the predictors of BAPI score of patients who consumed SC (table 3 ) and showed that out of PD value, age and heart rate, PD value was significantly and independently correlated with BAPI score $\left(\mathrm{r}^{2}\right.$ of the model $=$ $0.339 ; \mathrm{p}<0.001)$.

\section{Discussion}

In this study, the patients who consumed SC had significantly higher PD than healthy controls and PD was significantly correlated with BAPI score. Furthermore, the PD value was an independent predictor of BAPI score in patients who consumed SC.

Due to the increased risk of CVD in patients who consume SC, numerous clinical studies have been performed $[2,3,17,18]$. As a result of these studies, an increased proportion of young patients who consume SC contact the emergency services. In this study, patients who con- 
sumed SC were young (mean age: $26.9 \pm 7.0$ years), similar to previous reports [2]. Although the most frequently reported adverse clinical effect is tachycardia in young patients who consume SC [3], the mean heart rate in our study population was $71.3 \pm 12.7$ beats $/ \mathrm{min}$. In a recent study, Clark et al. [17] proposed that $\Delta 9$-tetrahydrocannabinol could cause an increase in sympathetic activity and leads to tachycardia at low or moderate doses of SC. Therefore, the tachycardia response and increased catecholamine concentrations could cause proarrhythmic abnormalities as well as increase the myocardial oxygen demand. In contrast, $\Delta 9$-tetrahydrocannabinol can also result in increased parasympathetic activity at higher doses of SC and cause hypotension and bradycardia [21]. Therefore, decreased coronary flow may contribute to myocardial ischemia. Harris and Brown [18] reported that SC might cause severe tachycardia and lead to serious health care conditions requiring evaluation in the emergency department [18]. Only 1 patient had tachycardia (102 beats/min) and 7 had bradycardia (minimum: 51 beats/min and maximum: 58 beats/min) in our study population. An absence of tachycardia and/or bradycardia may not exclude the adverse clinical effects of SC on the cardiovascular system. Although SC leads to proarrhythmic abnormalities, there is no clinical parameter to predict these abnormalities. Therefore, novel clinical parameters may be required to predict the effects of SC on the cardiovascular system.

We originally suggested the possible effect of SC on ECG parameters and then designed this study. We have found that the patients who consumed SC had significantly higher PD value than healthy controls. Therefore, our results demonstrated that SC may lead to an increased risk of CVD through prolongation of the PD. Due to the evaluation of the PD being less expensive and more widely available than other diagnostic modalities, clinicians rely upon it for the differential diagnosis of CVD. Previous studies had shown that PD is a noninvasive ECG marker that can be used to determine the increased risk of atrial fibrillation [22]. Increased PD has been reported in several clinical settings such as coronary artery disease, hypertension, chronic renal disease, hypertrophic cardiomyopathy, depression, heart failure, preeclampsia and metabolic syndrome [12, 13, 16, 23-27]. Although there are several pathways for the prolongation of $\mathrm{PD}$, the main mechanism observed in our patients was thought to be due to structural and electrophysiological changes in the atrial myocardium. There are several explanations for our results on ECG. Increased P-wave duration may be associated with altered autonomic control $[28,29]$. While the acute effect of SC may lead to sympathetic hyper-activation, their long-term use may trigger the parasympathetic system. Considering the effect of SC on the autonomic nervous system, their consumption may be one of the causes of increased PD. Addiction and withdrawal syndromes may also be a reason for increased PD [30].

In our study, although all laboratory parameters were within the normal range for the study population, detailed medical histories revealed the usage of SC. We did not validate the usage of SC with urine and/or blood tests. Although routine urine and blood samples are required for differential diagnosis in patients who consume SC, they are not enough for the diagnosis of SC consumption. Therefore, obtaining a detailed medical history and giving more attention to environmental factors are important methods for true diagnosis. In agreement with the literature $[1,3]$, patients who consumed SC had a low education level and the majority were also single. Therefore, lack of social support could contribute to the of drug abuse.

The limitations of this study were the small sample size and cross-sectional design. Lack of follow-up prospectively and the usage of SC should be validated by novel urine tests. We recommend a larger population sample to confirm these findings.

\section{Conclusions}

In this study, patients who consumed SC had significantly higher PD values than controls, and the BAPI score correlated with PD value. Furthermore, the PD value was an independent predictor of BAPI score. Hence SC consumption could lead to an increased risk of CVD through prolonged PD. We recommend the use of the simple and inexpensive ECG to assess cardiovascular risk in patients who consume SC.

References $\quad$ Castaneto MS, Gorelick DA, Desrosiers NA, et al: Synthetic cannabinoids: epidemiology, pharmacodynamics, and clinical implications. Drug Alcohol Depend 2014;144:12-41.

$\checkmark 2$ Winstock AR, Barratt MJ: The 12-month prevalence and nature of adverse experiences resulting in emergency medical presentations associated with the use of synthetic cannabinoid products. Hum Psychopharmacol 2013; 28:390-393.

3 Forrester MB: Adolescent synthetic cannabinoid exposures reported to Texas poison centers. Pediatr Emerg Care 2012;28:985-989. 
4 Sunbul M, Zincir SB, Durmus E, et al: Anxiety and depression in patients with coronary artery disease. Bull Clin Psychopharmacol 2013; 23:345-352.

$\checkmark 5$ Randall MD, Kendall DA, O’Sullivan S: The complexities of the cardiovascular actions of cannabinoids. Br J Pharmacol 2004;142:2026.

6 Sunbul M, Sunbul EA, Kosker SD, et al: Depression and anxiety are associated with abnormal nocturnal blood pressure fall in hypertensive patients. Clin Exp Hypertens 2014; 36:354-358.

7 Lippi G, Montagnana M, Favaloro EJ, et al: Mental depression and cardiovascular disease: a multifaceted, bidirectional association. Semin Thromb Hemost 2009;35:325-336.

$>8$ Kemp AH, Quintana DS, Gray MA, et al: Impact of depression and antidepressant treatment on heart rate variability: a review and meta-analysis. Biol Psychiatry 2010;67:10671074.

$>9$ Abate G, D’Andrea L, Battestini M, et al: Autonomic nervous activity in elderly dipper and non-dipper patients with essential hypertension. Aging (Milano) 1997;9:408-414.

10 Yılmaz R, Demirbağ R: P-wave dispersion in patients with stable coronary artery disease and its relationship with severity of the disease. J Electrocardiol 2005;38:279-284.

$\checkmark 11$ Tosu AR, Demir Ş, Kaya Y, et al: Association of $\mathrm{P}$-wave dispersion and left ventricular diastolic dysfunction in non-dipper and dipper hypertensive patients. Anadolu Kardiyol Derg 2014;14:251-255.

12 Atmaca M, Korkmaz H, Korkmaz S: P-wave dispersion in patients with hypochondriasis. Neurosci Lett 2010;485:148-150.
13 Tosu AR, Demir S, Kaya Y, et al: Increased QT dispersion and $\mathrm{P}$-wave dispersion in major depressive disorder. Exp Clin Cardiol 2013; 18:110-112.

14 Yavuzkir M, Atmaca M, Dagli N, et al: P-wave dispersion in panic disorder. Psychosom Med 2007;69:344-347.

15 Nussinovitch U: Meta-analysis of P-wave dispersion values in healthy individuals: the in fluence of clinical characteristics. Ann Noninvasive Electrocardiol 2012;17:28-35.

16 Dilaveris PE, Gialafos JE: P-wave dispersion: a novel predictor of paroxysmal atrial fibrillation. Ann Noninvasive Electrocardiol 2001;6: 159-165.

17 Clark BC, Georgekutty J, Berul CI: Myocardial ischemia secondary to synthetic cannabinoid (K2) use in pediatric patients. J Pediatr 2015; 167:757-761.

18 Harris CR, Brown A: Synthetic cannabinoid intoxication: a case series and review. J Emerg Med 2013;44:360-366.

19 Ögel K, Karadağ F, Evren C, et al: Bağımlılık Profil İndeksi (BAPİ) Uygulama Rehberi. Istanbul, Yeniden Yayınları, 2012.

20 Pac FA, Ballı S, Topaloğlu S, et al: Analysis of maximum $\mathrm{P}$-wave duration and dispersion after percutaneous closure of atrial septal defects: comparison of two septal occluders. Anadolu Kardiyol Derg 2012;12:249-254.

21 Ghuran A, Nolan J: Recreational drug misuse: issues for the cardiologist. Heart 2000;83: $627-633$.
22 Magnani JW, Johnson VM, Sullivan LM, et al: P-wave indices: derivation of reference values from the Framingham Heart Study. Ann Noninvasive Electrocardiol 2010;15:344-352.

23 İnci S, Nar G, Aksan G, et al: P-Wave dispersion and atrial electromechanical delay in patients with preeclampsia. Med Princ Pract 2015;24:515-521.

24 Ozdemir O, Soylu M, Demir AD, et al: P-wave durations as a predictor for atrial fibrillation development in patients with hypertrophic cardiomyopathy. Int J Cardiol 2004;94:163166.

25 Oylumlu M, Dogan A, Ozer O, et al: Effects of lying position on $\mathrm{P}$-wave dispersion in patients with heart failure. Med Princ Pract 2014;23:556-560.

26 Yilmaz H, Özcan KS, Sayar N, et al: Metabolic syndrome is associated with atrial electrical and mechanical dysfunction. Med Princ Pract 2015;24:147-152.

-27 Ozmen N, Cebeci BS, Kardesoglu E, et al: Relationship between $\mathrm{P}$-wave dispersion and effective hemodialysis in chronic hemodialysis patients. Med Princ Pract 2007;16:147-150.

28 Cheema AN, Ahmed MW, Kadish AH, et al: Effects of autonomic stimulation and blockade on signal-averaged $\mathrm{P}$ wave duration. J Am Coll Cardiol 1995;26:497-502.

29 Sattout AH, Nicol MF: Cardiac arrest following cannabis use: a case report. Cases J 2009; 2:208.

30 Zimmermann US, Winkelmann PR, Pilhatsch $\mathrm{M}$, et al: Withdrawal phenomena and dependence syndrome after the consumption of 'spice gold'. Dtsch Arztebl Int 2009;106: 464-467. 